\title{
Frontotemporal dementia: a clinical review
}

Harri Sivasathiaseelan ${ }^{1}$, Charles R Marshall ${ }^{1,2}$, Jennifer L Agustus ${ }^{1}$, Elia Benhamou ${ }^{1}$, Rebecca L Bond $^{1}$, Janneke EP van Leeuwen ${ }^{1}$, Chris JD Hardy ${ }^{1}$, Jonathan D Rohrer ${ }^{1}$, Jason D Warren ${ }^{1}$

1. Dementia Research Centre, UCL Queen Square Institute of Neurology, University College London, London, United Kingdom

2. Preventive Neurology Unit, Wolfson Institute of Preventive Medicine, Queen Mary University of London, London, United Kingdom

Correspondence to: Prof. Jason Warren

Dementia Research Centre

UCL Queen Square Institute of Neurology

University College London

London WC1N 3BG

Email: jason.warren@ucl.ac.uk

Tel: +44 [0]203 4484773

Fax: +44 [0]203 4483104 


\begin{abstract}
The frontotemporal dementias are a clinically, neuroanatomically and pathologically diverse group of diseases that collectively constitute an important cause of younger onset dementia. Clinically, the frontotemporal dementias characteristically strike capacities that define us as individuals, presenting broadly as disorders of social behaviour or language. Neurobiologically, these diseases can be regarded as 'molecular nexopathies', a paradigm for selective targeting and destruction of brain networks by pathogenic proteins. Mutations in three major genes collectively account for a substantial proportion of behavioural presentations, with far-reaching implications for the lives of families but also potential opportunities for presymptomatic diagnosis and intervention. Predicting molecular pathology from clinical and radiological phenotypes remains challenging, however certain patterns have been identified and genetically mediated forms of frontotemporal dementia have spearheaded this enterprise. Here we present a clinical roadmap for diagnosis and assessment of the frontotemporal dementias, motivated by our emerging understanding of the mechanisms by which pathogenic protein effects at cellular level translate to abnormal neural network physiology and ultimately, complex clinical symptoms. We conclude by outlining principles of management and prospects for disease modification.
\end{abstract}




\section{INTRODUCTION}

Frontotemporal dementia (FTD) is a clinically, neuroanatomically and pathologically heterogeneous group of neurodegenerative diseases that share a propensity to target the frontal and temporal lobes of the brain ${ }^{1}$. Although substantially less common than Alzheimer's disease, the disorders that comprise the FTD spectrum have disproportionate clinical and neurobiological importance. From a clinical perspective, FTD usually presents as a disturbance of complex behaviour, affecting predominantly inter-personal conduct or language (primary progressive aphasia, PPA), often in middle life; it is the major young onset dementia besides Alzheimer's disease, and takes a devastating toll on social and occupational functioning. Moreover, a substantial proportion of cases are genetically mediated, with implications for family counselling and presymptomatic diagnosis. From a neurobiological perspective, FTD illustrates the effects of pathogenic proteins in promoting selective disintegration of neural assemblies and has transformed our understanding of the molecular and network mechanisms of neurodegenerative disease.

The FTD spectrum encompasses three canonical clinico-anatomical variant syndromes, classified according to their leading features ${ }^{1,2}$. Behavioural variant FTD (bvFTD), the commonest of the major FTD phenotypes, presents with progressive decline in emotional reactivity and interpersonal and executive skills, associated with a variable profile of fronto-temporal atrophy. Semantic variant primary progressive aphasia (svPPA) presents with loss of vocabulary and ultimately degrades semantic knowledge of sensory objects and nonverbal concepts as well as words; it is characteristically associated with focal atrophy chiefly affecting the left antero-mesial temporal lobe. Nonfluentagrammatic variant primary progressive aphasia (nfvPPA) presents with impaired motor speech production and/or sentence construction, associated with relatively focal, predominantly left anterior peri-Sylvian atrophy. As they evolve, these syndromes overlap extensively with each other and with syndromes of atypical parkinsonism (progressive supranuclear palsy, PSP and corticobasal 
degeneration syndrome, CBS) and less frequently, motor neuron disease (MND). A third progressive aphasia syndrome, logopenic aphasia ${ }^{3}$, is typically (though by no means inevitably) a variant presentation of Alzheimer's disease.

While clinical presentations compatible with FTD have been described for well over a century, the first detailed clinical and neuropathological descriptions were made by Arnold Pick ${ }^{4,5}$. In the modern era, interest was rekindled by recognition of the syndromes of semantic dementia ${ }^{6}$ and slowly progressive aphasia without generalized dementia'. This led to the formulation of 'frontal dementia'8,9, the original Lund-Manchester consensus criteria for clinical diagnosis ${ }^{10}$ and identification of the first causative gene mutation ${ }^{11}$. Subsequent progress has been meteoric, with updating of diagnostic criteria for the canonical syndromic variants of $\mathrm{FTD}^{12,13}$, delineation of all major genetic, neuropathological and neuroanatomical substrates ${ }^{14,15,16,17}$ and creation of multi-centre international collaborations dedicated to presymptomatic diagnosis and therapeutic trial design ${ }^{18}$. However, robust and sensitive biomarkers of disease course and molecular pathology and effective therapies remain elusive and are presently the focus of an intense international research effort.

\section{EPIDEMIOLOGY}

Limited data suggest that the overall population prevalence of FTD is around 11/100,000 and incidence $1.6 / 100,000^{19}$ but these values rise sharply between the fifth and seventh decades and are likely to be underestimates (chiefly on account of misdiagnosis), particularly in older age groups. FTD accounts for around $40 \%$ of cases of young onset dementia coming to post mortem ${ }^{20}$; onset is most often in middle life, but ranges very widely between the third and ninth decades. It has been proposed that developmental dyslexia (as a marker of intrinsic language system vulnerability) may predispose to subsequent emergence of primary progressive aphasia ${ }^{21}$ and certain population-level genetic risk factors have been identified ${ }^{22}$; however, the factors that promote sporadic FTD remain essentially unknown and we still lack stratified epidemiological data for different ethnic and socio-economic 
groups.

\section{DISEASE NEUROBIOLOGY}

\section{Histopathology}

The common pathological mechanism underpinning FTD is intracellular deposition of abnormally aggregated proteins in neural tissue ${ }^{23}$. Accordingly, diseases in the FTD spectrum are 'proteinopathies' and can be classified according to the major constituents of the cellular inclusions present (Figure 1). Around half of cases coming to post mortem have abnormal deposition of transactive response DNAbinding protein 43 (TDP-43), which is ubiquitously expressed and broadly implicated in neuronal development and synaptic function; these cases are variably associated with neuronal cyotoplasmic and intranuclear inclusions and dystrophic neurites ${ }^{23}$, and can be subclassified according to the morphology and laminar distribution of the cellular inclusions ${ }^{17}$. Around $40 \%$ of post mortem cases have abnormal accumulation of hyperphosphorylated microtubule-associated protein tau, which is likely to disrupt axonal transport and maintenance of neuronal integrity; these cases can be subclassfied immunohistochemically according to whether abnormally deposited tau contains predominantly threeor four-repeat microtubule binding domains. A small minority of cases have deposition of a family of fusion oncogene proteins, involved in DNA and RNA metabolism; rarely, none of these proteins is present. The mechanisms via which these pathogenic proteins give rise to neurodegeneration and cell death continue to be defined ${ }^{23}$.

\section{Molecular genetics}

A substantial proportion of the FTD spectrum comprises genetically mediated diseases; this proportion varies widely between clinical syndromes, the most heritable being bvFTD and the least heritable svPPA $^{24}$. In bvFTD, an autosomal dominant familial inheritance pattern signifying a pathogenic mutation may be elicited in $10-20 \%$ of cases and some history suggesting affected family members in

a higher proportion ${ }^{2,25,26}$. Three major causal genes account for the large majority $(>80 \%)$ of cases of 
familial FTD, with wide geographical variation in relative frequency, likely attributable to founder effects. Abnormal expansion of a hexanucleotide repeat on the open reading frame on chromosome 9 (C9orf72), the most recently identified major genetic factor, is the most common cause of genetic FTD (and MND) worldwide, accounting for some $25 \%$ of familial FTD and 5\% of apparently sporadic FTD $^{27}$. Mutations in the progranulin $(G R N)$ gene mutations account for a similar proportion of familial FTD and $1-5 \%$ of apparently sporadic cases $^{28}$. Mutations in the microtubule-associated protein tau (MAPT) gene also account for a substantial number of familial FTD cases though the proportion varies widely across series ${ }^{29,30,31}$. Mutations in a range of other genes collectively account for a minority of cases of familial FTD and (along with C9orf72) are particularly relevant to the overlap FTD-MND spectrum $^{23}$; of these, mutations in the TANK-binding kinase $1(T B K 1)$ gene may be numerically the most significant ${ }^{32}$. MAPT mutations are associated with abnormal phosphorylated tau deposition whereas TDP-43 pathology is found in association with most other mutations (Figure 1).

There is much interest in identifying genetic associations that might act as risk factors or phenotypic modifiers for the wider burden of sporadic FTD. Genome-wide association surveys have identified a number of potentially relevant factors, of which the best characterised are variants in TMEM106B $22,33,34$.

\section{Predicting molecular pathology}

A grail of neurodegenerative disease research is to uncover the mechanisms whereby molecular pathologies give rise to complex phenotypes and conversely, to predict the underlying proteinopathy from phenotypic features. This issue has important implications for understanding disease neurobiology, for clinical diagnosis, and ultimately, for development and rational use of diseasemodifying therapies. A key paradigm across the neurodegenerative disease spectrum is the destruction of neural circuits and macroscopic networks by 'prion-like' spread of pathogenic proteins, informed by vitro and animal models ${ }^{23,35}$. While core clinical phenotypes of FTD have been compellingly linked to 
intrinsic large-scale brain networks ${ }^{14}$, network and phenotypic signatures of particular proteinopathies are less well established. Certain correspondences have been derived from combined neuropathological, genetic, neuroimaging and neuropsychological studies ${ }^{16,36,37}$ (see Figure 1) and these have been endorsed by neuroanatomical measures of earliest change in genetically defined FTD $^{18}$. This has led to the proposal that diseases in the FTD spectrum may constitute 'molecular nexopathies': specific conjunctions of pathogenic protein and neural circuit characteristics. This idea has received some support from computational modelling and human functional neuroimaging studies $^{38,39}$. However, individual variation and convergence of phenotypes as disease evolves greatly complicate the picture. Moreover, the closeness of the correspondence varies between proteins and phenotypes: whereas (for example) TDP type C pathology is closely aligned with semantic dementia and 4-repeat tau pathology with PSP, bvFTD is associated with a variety of neuroanatomical patterns and proteinopathies. This may in part reflect the difficulty of deconstructing complex clinical phenotypes, motivating the search for physiological markers of neural circuit dysfunction that may underpin such phenotypes and at the same time, may more closely reflect underlying molecular pathology (see Box 1).

\section{CLINICAL DIAGNOSIS}

\section{General considerations}

Accurate diagnosis of FTD syndromes is challenging: clinicians' experience of these diseases is often limited, and presentations dominated by personality change or aphasia are readily misinterpreted as psychiatric illness, stroke or other conditions, especially in the earlier stages. On the other hand, 'overinterpretation' of brain atrophy on neuroimaging sometimes leads to a spurious diagnosis of FTD. Interviewing an informant is essential to form an accurate picture of the illness, particularly as communication problems or lack of insight may vitiate the patient's own account. A detailed neurological examination is required to identify associated extrapyramidal or motor neuron deficits that 
frequently develop during the course of the disease. Neuroimaging, ideally with MRI and interpreted by an experienced observer, is essential to corroborate the bedside impression; and where available, neuropsychological assessment is very valuable, to quantify key deficits and their evolution over time (which may be decisive in clinically ambiguous cases) and also to capture associated cognitive deficits that help to define the phenotype.

In light of the major role played by pathogenic genetic mutations in FTD, a searching family history is mandatory. This is particularly pertinent in bvFTD. Potentially relevant family history extends to 'psychiatric' disorders and MND and it should be borne in mind that 'dementia' and 'Alzheimer's disease' were used clinically as catch-all diagnoses until comparatively recently. If parents are deceased, ages at death should be documented. A significant number of FTD cases with confirmed mutations lack a recognised family history: this may reflect misdiagnosis as well as censoring.

We now highlight principles that we have found useful in identifying canonical FTD syndromes and differentiating these from other disorders. It is important to recognise, however, that FTD not uncommonly presents with fragmentary or mixed phenotypes, not conforming closely to the simplified scheme presented here.

\section{Behavioural variant FTD}

This syndrome is characterised by early, progressive decline in interpersonal and executive skills and loss of social and emotional awareness. Current diagnostic criteria ${ }^{12}$ foreground a number of domains of behavioural and personality change derived from the history, notably social disinhibition, apathy and abulia (loss of motivation and initiative), emotional blunting with loss of empathy, perseverative, stereotyped or compulsive verbal and motor routines (often involving hoarding, counting or tidying), hyeperorality and altered feeding behaviour with a tendency to gluttony and sweet tooth. The criteria further emphasise executive dysfunction with relative sparing of episodic memory and visuospatial functions on neuropsychological assessment; and rank the diagnosis as possible, probable or definite, 
based on the availability of corroborative neuroimaging, genetic or histopathological information.

These criteria have been instrumental in improving recognition and furthering research in FTD internationally but there are several caveats on their bedside application. bvFTD is a strikingly diverse syndrome, both clinically and neurobiologically. Behavioural symptoms are protean and typically shift over time; the syndrome commonly presents in fragmentary form, many patients perform well on formal neuropsychological testing of executive function and the most telling features (such as loss of inter-personal warmth) are particularly difficult to quantify in the clinic. Social infringements may mean the patient is first seen by psychiatric or forensic services ${ }^{40}$. On the other hand, it is increasingly recognised that deficits of episodic memory are not uncommon in bvFTD while executive dysfunction is not particularly helpful in discriminating FTD from Alzheimer's disease ${ }^{41}$ and posterior parietal cortical dysfunction may be prominent in some scenarios (such as $G R N$ mutations $^{42}$ ). Arguably more than any other syndrome in cognitive neurology, early diagnosis of bvFTD relies on a finessed history from an informant who knows the patient well. However, even the history of progressive functional decline - generally considered a tenet of dementia diagnosis - may be difficult to establish: a substantial minority of patients have a 'phenocopy syndrome' in which neuroimaging is normal and objective evidence of deterioration is lacking despite often eloquent testimony from the spouse or other caregivers. The basis for this phenocopy syndrome is still not clear: for unknown reasons, it appears to be more common in older males, and some cases have been found to harbour a $C 9$ orf 72 mutation $^{43}$.

Certain other clinical features that point to bvFTD are not emphasised in the current criteria ${ }^{2}$. These include impaired social cognition (inability to interpret other people's mental states and feelings and loss of awareness of social mores) and in tandem with this, altered sense of humour with a preference for nasty or slapstick comedy ${ }^{44}$; lack of insight regarding the effects of the illness, leading to reckless or ill-advised financial and other decisions; altered (usually, reduced) libido and affection ${ }^{45}$; and altered sensitivity to sound, pain and temperature ${ }^{46,47}$. New preoccupations may shift away from the inter- 
personal toward more 'abstract' artistic or musical pursuits ${ }^{46,48}$. Psychotic features including delusions and hallucinations or prominent anxiety and other affective disturbances may develop, more commonly in association with C9orf72 mutations and $\mathrm{MND}^{36,49}$. Language impairment frequently emerges later in the course of bvFTD: this tends to manifest as anomia and semantic deficits, signaling convergence with the syndromic spectrum of progressive aphasia, particularly svPPA ${ }^{50}$.

On examination, the quality of the patient's interactions with the examiner and other people are often more telling than their performance on cognitive tests; clues may include lack of insight into the difficulties recounted on the informant's history, rude remarks or loss of social boundaries, profound inertia or impassivity (loss of social facial reactivity), failure to read a spouse's emotions, distractibility, impulsivity, perseveration or environmental dependency (spontaneous handling of objects in the vicinity). Although the general neurological examination at presentation is often normal, many patients will develop parkinsonism (merging with the CBS - PSP spectrum) or MND features. Primitive reflexes and 'frontal release signs' tend to emerge late and are not particularly helpful diagnostically.

Brain MRI at presentation generally shows a degree of frontal and/or temporal lobe atrophy, but this varies widely in severity and regional distribution, within and between the cerebral hemispheres, and is importantly modulated by the underlying molecular pathology (Figure 1). This variability maps onto separable clinico-anatomical sub-syndromes of bvFTD ${ }^{16,51}$, albeit with extensive overlap in individual patients. Among these, the syndrome associated with focal right temporal lobe atrophy is especially striking, with profound loss of emotional reactivity and awareness, topographical difficulties and sometimes unusual phenomena such as hyperreligiosity, hallucinations and cross-modal sensory experiences $^{52}$; inability to recognise familiar faces (prosopagnosia) may be a leading feature, as part of a more general failure of social signal processing which also extends to abnormal physiological responses $^{53}$, and as the syndrome evolves it overlaps increasingly with svPPA. Where MRI in bvFTD is 
initially inconclusive, serial MRI studies at a yearly interval may document progressive brain atrophy and corroborate a clinical impression of deterioration. Functional neuroimaging (for example, FDGPET) has a limited role in diagnosis though may occasionally reveal regional hypometabolism where structural brain MRI is inconclusive.

\section{Semantic variant primary progressive aphasia}

The hallmark of this syndrome - also known as semantic dementia - is progressive breakdown of semantic memory: the memory system that mediates our cumulative knowledge of words, objects and concepts (in contrast, episodic memory - the store of autobiographical events - is particularly targeted by Alzheimer's disease). Typically, svPPA presents as loss of vocabulary: there is characteristically a history of 'forgetting the names' of items, asking the meaning of familiar spoken or written words, and when reading aloud, a tendency to regularise words according to their surface orthography ('surface' dyslexia or dysgraphia; for example, sounding or spelling 'sew' as 'soo'). The patient's speech is, at least initially, easily passed as normal; it is fluent (even garrulous) and well-structured. However, mounting reliance on circumlocutions and imprecise approximations (e.g., 'sparrow' becomes 'bird' and ultimately 'animal' or 'thing') renders conversation increasingly empty of substance. Evolving nonverbal semantic impairment leads to prosopagnosia, visual and other sensory agnosias. A behavioural syndrome overlapping with bvFTD generally supervenes; obsessions centred on time with clock-watching and puzzles such as jigsaws and Sudoku are often particularly striking ${ }^{3}$, hyperacusis, tinnitus and abnormal sensitivity to bodily sensations (manifesting as somatic symptoms ${ }^{46,47,54,55}$ ) are common and impoverished self-and future-concepts may lead to nihilism and suicidality ${ }^{56,57}$. Perceptual, praxic, arithmetical and navigational skills are generally well preserved.

On examination, anomia is generally marked but (because impaired naming or word retrieval occurs in a variety of settings) diagnosis rests on demonstrating impaired comprehension of single words (for example, by asking the patient to define or point to pictured items nominated by the examiner $)^{3}$. Speech 
is grammatical with normal articulation and prosody, and verbal working memory (indexed by repetition of polysyllabic words and phrases), visuospatial and other parieto-occipital cortical functions are intact. The general neurological examination is usually unremarkable at presentation though extrapyramidal and corticospinal signs may emerge later in the illness ${ }^{58,59}$.

This clinical phenotype of svPPA is associated with a hallmark MRI signature of focal, asymmetric cerebral atrophy predominantly affecting the antero-medial and inferior temporal lobes, usually more marked on the left (Figure 1). There is stark involvement of temporal pole (which typically shows a 'knife-blade' appearance due to marked gyral destruction), amygdala, anterior hippocampus and fusiform gyrus. So consistent is this profile (in contrast to the rather variable MRI profiles of other FTD syndromes) that the diagnosis should be questioned if it is absent. Typical svPPA is generally sporadic $^{2,3}$, though we have seen it mimicked occasionally by MAPT, C9orf72 or TBK1 mutations.

\section{Nonfluent - agrammatic variant primary progressive aphasia}

This syndrome principally affects speech production and presents with effortful, hesitant, poorly constructed speech. It is more likely than other FTD syndromes to present in later life ${ }^{19}$. There is often a history of mispronouncing longer words and sometimes reappearance of a childhood stutter. Speech errors are frequent: with variable prominence, these affect individual speech sounds (manifesting as defective syllable selection - phonological errors - or articulation - phonetic errors), whole words (manifesting as defective selection between alternative responses, such as confusion of 'Yes/ No', 'his/her' - 'binary reversals' ${ }^{60}$ and sentences (grammatical errors). Articulatory difficulty or 'speech apraxia' often dominates the presentation and in pure form has been proposed to constitute a distinct sub-syndrome ${ }^{61}$, though other language deficits frequently emerge over time. As the illness unfolds, grammatical and spelling errors generally appear in the patient's written output and comprehension of more complex messages is reduced, reflect deficits of receptive grammar or central auditory processing ${ }^{3,62,63}$. Many patients develop parkinsonism and features of the CBS - PSP spectrum (or less 
commonly, MND) and swallowing often becomes affected. Executive dysfunction, apathy and depression (reflecting retained insight) are also frequent issues ${ }^{25}$, though many patients have remarkably preserved general intellect.

On examination, there is generally obvious dysfluency; speech is marred by sound errors and may have a telegraphic quality due to omission of connecting words, though agrammatism is more reliably assessed from written sentence production. More subtle motor speech impairment can be brought out by asking the patient to repeat a sequence of syllables (such as 'puh - ta - kuh'), which taxes articulatory agility. Repetition of polysyllabic words and phrases is comparably affected. There is often associated apraxia of posed orofacial movements such as yawning or whistling. Dominant parietal signs such as dyslexia (predominantly affecting the sounding of non-words such as proper names that rely on phonological decoding rather than vocabulary), limb apraxia and verbal working memory impairment and extrapyramidal signs such as supranuclear gaze palsy, limb rigidity, dystonia and postural instability frequently develop ${ }^{3,25,64}$, signifying spread of disease within peri-Sylvian cortical and cortico-subcortical networks. Patients with underlying CBS - PSP pathology tend to have reduced spontaneous language output disproportionate to the degree of motor speech impairment, and this 'dynamic aphasia' may sometimes lead the presentation ${ }^{3,65,66}$.

Brain MRI characteristically shows asymmetric atrophy of inferior frontal gyrus, insula and anterior superior temporal gyrus, more marked on the left (Figure 1); however, individual patients show atrophy profiles that vary widely in severity and posterior cortical extension. In ambiguous cases, serial MRI to assess progressive regional atrophy is often helpful. There may be associated atrophy of the midbrain and other subcortical structures ${ }^{67}$. While nfvPPA is substantially less likely to be genetically mediated than bvFTD, causative mutations are well documented ${ }^{2}$ and should be suspected where there is a relevant family history, suggestive MRI profile (Figure 1) or 'complex' mixed aphasic syndrome (associated, in particular, with $G R N$ mutations $^{3,62,68}$ ). 


\section{Differential diagnosis}

The key diagnostic priorities in a patient presenting with a syndrome compatible with FTD are to identify treatable or reversible processes that simulate FTD; and within the FTD spectrum, to identify genetic processes that may have implications for counselling or screening other family members. The distinction from primary psychiatric illness is relevant to all FTD syndromes, particularly in bvFTD and where psychotic features are present: this is generally resolved by neuroimaging but requires an initial index of suspicion, especially when a neuropsychiatric syndrome develops de novo in later life or with unusual features (such as abnormal eating behavior or faux pas). Language disorders can present with rather counter-intuitive symptoms, whereas isolated non-organic speech disorders are rare; an expert second opinion may be worthwhile.

A fronto-subcortical cognitive syndrome with variably prominent executive and attentional compromise, neuropsychiatric changes and cognitive slowing is the final common pathway of many brain diseases, including potentially remediable surgical and inflammatory processes. In older people, cerebrovascular disease and (less commonly) dementia with Lewy bodies can closely simulate bvFTD, while in young adults, rare metabolic and genetic illnesses expand the differential diagnosis ${ }^{69,70}$. Neuroimaging in conjunction with a careful history and examination will often distinguish these diseases from the primary FTD spectrum. Identifying patients with probable underlying Alzheimer pathology is important in prognosis and future planning but also consideration of symptomatic therapy with acetylcholinesterase inhibitors. In the spectrum of language presentations, Alzheimer's disease is most reliably signaled by logopenic aphasia, which presents with anomia and word finding pauses without the profound semantic impairment of svPPA or the articulatory and agrammatic errors of nfvPPA but with disproportionate difficulty repeating phrases and sentences versus single words, reflecting a core deficit of verbal working memory linked to involvement of dominant temporo-parietal cortex $^{3}$. More problematic is the 'frontal variant' of Alzheimer's, presenting with prominent executive 
or behavioural changes ${ }^{71}$; this can be particularly difficult to distinguish clinically from FTD in the individual case, underlining the value of CSF examination or amyloid-PET neuroimaging to identify Alzheimer biomarkers, especially in younger patients.

A 'diagnostic mandala' for FTD emphasising key differentiating clinical, neuroimaging and laboratory features of major phenotypes and underlying pathologies is summarised in Figure 2.

\section{OUTLOOK AND MANAGEMENT}

\section{General considerations}

No treatments have currently been shown to alter the underlying disease process in any FTD syndrome. The prognosis in FTD is therefore one of steadily increasing disability and ongoing decline to dependency. However, life expectancy varies widely across the FTD spectrum ${ }^{19,72}$, ranging from a few years in FTD - MND to over a decade in some patients with bvFTD and svPPA. As the disease evolves, syndromes tend to converge and non-cognitive neurological features often develop ${ }^{73}$. However, we currently lack reliable markers of disease severity, stage and prognosis to inform counselling of individual patients and families.

Management of FTD begins with provision of accurate information about the nature of the illness to the patient, family members, caregivers and relevant health professionals. This is a truly life-changing diagnosis: erosion of the sufferer's personal identity ('living with a stranger') can be profoundly distressing for those close to them. Understanding its impact on the patient's social milieu, day-to-day

functioning and care needs, together with appropriate safe-guarding and anticipating future loss of independence are integral to managing the illness successfully. There are a number of excellent on-line resources (for example: http://ecdc.org.au/ftd-toolkit.htm) and access to a local or national lay support group oriented to FTD (http://www.raredementiasupport.org/groups/) can be a transformative source of practical advice and informal counselling. Practical and emotional support and regular respite for caregivers are integral to successful management but easily overlooked. 
Table 1 presents a problem-based management 'checklist' under the broad themes of optimising quality of life, controlling symptoms, supporting caregivers and planning for the future. Given the current dearth of adequate clinical trials, management recommendations in FTD are based largely on clinical experience and anecdote.

\section{Non-pharmacological strategies}

In general, for control of symptoms non-pharmacological strategies are preferable to medications, which are difficult to use rationally, of limited efficacy and prone to produce unwelcome side effects in people with FTD. This in turn requires engagement of local multidisciplinary support services, such as speech and language and occupational therapy, audiology, clinical psychology and social work, ideally coordinated by the general practitioner and/or local community mental health team. Caregivers may need to be educated and empowered to take an active management role. Patients benefit from a stable and structured environment tailored to their particular capacities and interests; safe-guarding is essential, encompassing (for example) activities linked to occupation, hobbies, responsibility for children or elderly dependents, financial decision making and driving. The last is often particularly challenging where manual competence is retained but judgment and insight are compromised. Communication is an important issue across syndromes and disease stages, particularly in the progressive aphasias. While the place of specific language retraining programmes and electronic devices remains undefined ${ }^{3}$, there is unquestionable value in simple communication aids such as cards, picture books and medical alert bracelets. As the disease evolves, the focus of management shifts from maintaining independence to controlling aggression and other challenging behaviours and addressing neurological disability due to declining mobility, impaired swallowing and nutrition and disturbed homeostatic and autonomic functions. It is important that general medical health needs are not overlooked in the face of anosognosia or altered awareness of pain and other bodily signals.

\section{Pharmacotherapy}


There is a place for pharmacotherapy in FTD where non-pharmacological strategies are ineffective. Use of acetylcholinesterase inhibitors and memantine is worthwhile in patients with biomarker evidence of Alzheimer's pathology but evidence of benefit in other cases of FTD is not secure and some patients may experience an escalation of behavioural disturbance ${ }^{74,75}$. As serotonergic function is reduced in $\mathrm{FTD}^{76}$, use of serotonergic modulators is more apposite a priori and modest behavioural

benefit has been shown for trazodone and citalopram though not paroxetine ${ }^{77,78,79}$. Neuroleptic medication may be required to manage psychosis, intractable aggression or intrusive compulsions though care is needed, as patients with FTD are at risk of significant extrapyramidal side effects, even with newer generation agents ${ }^{80,81}$; in this situation we favour low-dose risperidone or quetiapine, with close clinical monitoring.

\section{Genetic testing and the family}

The issue of genetic testing in FTD is a complex one for which clear guidelines are currently lacking. The case is most straightforward where there is a family history of FTD, young onset dementia, major psychiatric disorder or MND, particularly with the suggestion of autosomal dominant inheritance. We have a low threshold for screening genetic mutations in any patient with FTD (in particular, bvFTD) where the findings would be potentially important for other family members (for example, adult children planning their own families) and the family should be involved in the decision to do an initial diagnostic test. If a causative mutation is found, it is often helpful to meet with at-risk family members separately to talk through the nature of the illness and specific implications relevant to them. As with any genetic illness, those who would like to take matters further should be referred for counselling with an experienced geneticist prior to deciding whether to have a presymptomatic test. Although general correlations can be identified at population level ${ }^{82}$, it is not possible currently to offer reliable and specific advice regarding likely age at onset or indeed, initial symptoms, should a pathogenic mutation be identified presymptomatically. 


\section{FUTURE PROSPECTS}

The field of FTD research and practice is poised at an exciting juncture. Future progress will depend on translating recent unprecedented advances in pathobiology to improved methods of diagnosis, disease tracking and ultimately, disease-modifying therapies.

The finding that molecularly-determined structural changes in major genetic forms of FTD precede the onset of clinical symptoms by many years was an important milestone suggesting that presymptomatic disease detection and intervention is feasible, at least in principle ${ }^{18}$. Furthermore, this was only made possible by the creation of a multi-centre international collaboration (the Genetic Frontotemporal Dementia Initiative, GenFI), allowing data from families with rare mutations to be acquired, pooled and analysed on a common platform. GenFI and the US-based Longitudinal Evaluation of Familial Frontotemporal Dementia and Advancing Research and Treatment for Frontotemporal Lobar Degeneration projects ${ }^{83}$ are equipped to drive large-scale clinical trials of disease-modifying therapies covering the FTD spectrum, as these become available, from the earliest stages of disease. To date, studies of FTD trial methodology and sample size estimates have focused on structural MRI ${ }^{84}$ : essentially, a measure of cell death (brain atrophy). This is a blunt tool with which to assess disease and treatment effects. Ideally, sensitive and dynamic biomarkers are required that provide a 'read-out' of cellular and synaptic function, to identify the culprit protein and its physiological impact before irrecoverable neural damage occurs and to determine rapidly if candidate treatments are working. The heterogeneity of FTD means that biomarker development is a more challenging proposition in this group of diseases than in (for example) Alzheimer's disease. However, there is currently considerable interest in identifying genetic risk factors and modifiers in sporadic FTD from genome-wide association studies ${ }^{33}$, new tools such as molecular ligand neuroimaging that can capture deposition of protein tau in vivo ${ }^{85}$ and wet biomarkers derived from CSF and blood assays of proteins such as tau and its metabolites, neurofilament light chain, TREM2 and progranulin ${ }^{86-90}$ : these approaches may detect 
and track neuronal injury and dysfunction more closely than has previously been possible. In addition, there is growing awareness of the systemic metabolic and physiological correlates of deranged homeostatic processing in $\mathrm{FTD}^{91,92}$. Complementary tools derived from functional neuroimaging, autonomic and electrophysiology $y^{39,53,88,93}$ address neural network dysfunction and may yield proxies of complex clinical phenotypes that are difficult to measure directly. Multimodal biomarkers combining these different measures may provide the most sensitive and specific pathophysiological indices of underlying pathogenic protein activity ${ }^{88,94}$.

A number of promising candidate approaches to disease modifying therapy are now entering trials. Individuals with known genetic mutations or highly predictable, sporadic pathology based on clinical phenotype (such as tauopathy in progressive supranuclear palsy) form the logical initial target groups. Such work has a crucial preclinical phase via drug discovery and development of therapeutic approaches in vitro and animal models, including pluripotent stem cells derived from patients with defined diseases and transgenic mice that can be used to generate model neuronal systems ${ }^{95,96,97}$. Proposed disease-modification strategies have included anti-tau antibodies and microtubule stabilisation, stimulation of progranulin expression and release, modulation of autoimmunity and neuroinflammation (particularly relevant to $G R N$ mutations) and, most dramatically (informed by recent progress in Huntington's disease), silencing of toxic C9orf72 RNA messengers using anti-sense oligonucleotides $^{83,98}$. To date, the value and feasibility of these strategies remain unproven in FTD. Alongside disease modification, there is a need to develop rational and effective, pathophysiologically informed interventions for harnessing residual capacities ${ }^{99}$ and controlling symptoms: recent examples include the use of intranasal oxytocin for redressing emotional indifference in FTD syndromes ${ }^{100}$ and cognitive rehabilitation and transcranial stimulation techniques in the progressive aphasias ${ }^{101,102}$. Such interventions are likely to become even more relevant as effective disease modifying therapies become available. 


\section{Acknowledgments}

This work was supported by the Wolfson Foundation, the Alzheimer's Society, Alzheimer's Research

UK, Brain Research UK, Action on Hearing Loss, the Dunhill Medical Trust, the Wellcome Trust, the Medical Research Council, the National Brain Appeal and the NIHR UCLH Biomedical Research Centre. 


\section{References}

1. Warren JD, Rohrer JD, Rossor MN. Clinical review. Frontotemporal dementia. BMJ. 2013a; 347: f4827.

2. Woollacott IO, Rohrer JD. The clinical spectrum of sporadic and familial forms of frontotemporal dementia. J Neurochem. 2016 Aug;138 Suppl 1:6-31.

3. Marshall CR, Hardy CJD, Volkmer A, Russell LL, Bond RL, Fletcher PD, Clark CN, Mummery CJ, Schott JM, Rossor MN, Fox NC, Crutch SJ, Rohrer JD, Warren JD. Primary progressive aphasia: a clinical approach. J Neurol. 2018a Jun; 265(6): 1474-1490.

4. Pick A. Über die Beziehungen der senilen Hirnatrophie zur Aphasie. Prag Med Wochenschr 1892; 17: 165 -167.

5. $\quad$ Pick A. Über primare progressive Demenz bei Erwachsenen. Prag Med Wochenschr 1904; 29: $417-420$.

6. Warrington EK. The selective impairment of semantic memory. Q J Exp Psychol. 1975 Nov; 27(4): 635-57.

7. Mesulam MM. Slowly progressive aphasia without generalized dementia. Ann Neurol. 1982; 11(6): 592-8.

8. Gustafson L. Frontal lobe degeneration of non-Alzheimer type, II: clinical picture and differential diagnosis. Arch Gerontol Geriatr. 1987; 6: 209223.

9. Neary D, Snowden JS, Northern B, Goulding PJ. Dementia of the frontal lobe type. J Neurol Neurosurg Psychiatry. 1988; 51: 353-361.

10. Brun A, Englund B, Gustafson L, et al. Clinical and neuropathological criteria for frontotemporal dementia. J Neurol Neurosurg Psychiatry. 1994 Apr;57(4):416-8.

11. Hutton M, Lendon CL, Rizzu P, et al. Association of missense and 5'-splice-site mutations in tau with the inherited dementia FTDP-17. Nature. 1998; 393: 702-705.

12. Rascovsky K, Hodges JR, Knopman D, Mendez MF, Kramer JH, Neuhaus J, et al. Sensitivity of revised diagnostic criteria for the behavioural variant of frontotemporal dementia. Brain. 2011 Sep; 134(Pt 9): 2456-77. 
13. Gorno-Tempini ML, Hillis AE, Weintraub S, Kertesz A, Mendez M, Cappa SF, et al. Classification of primary progressive aphasia and its variants. Neurology. 2011 Mar 15; 76(11): 100614.

14. Seeley WW, Crawford RK, Zhou J, Miller BL, Greicius MD. Neurodegenerative diseases target large-scale human brain networks. Neuron. 2009 Apr 16;62(1):42-52.

15. Rohrer JD, Warren JD. Phenotypic signatures of genetic frontotemporal dementia. Curr Opin Neurol. 2011 Dec; 24(6): 542-9.

16. Rohrer JD, Lashley T, Schott JM, Warren JE, Mead S, Isaacs AM, et al. Clinical and neuroanatomical signatures of tissue pathology in frontotemporal lobar degeneration. Brain. 2011 Sep;134(Pt 9):2565-81.

17. Mackenzie IR, Neumann M, Baborie A, Sampathu DM, Du Plessis D, Jaros E, Perry RH, Trojanowski JQ, Mann DM, Lee VM. A harmonized classification system for FTLD-TDP pathology. Acta Neuropathol. 2011 Jul;122(1):111-3.

18. Rohrer JD, Nicholas JM, Cash DM, van Swieten J, Dopper E, Jiskoot L, et al. Presymptomatic cognitive and neuroanatomical changes in genetic frontotemporal dementia in the Genetic Frontotemporal dementia Initiative (GENFI) study: a cross-sectional analysis. Lancet Neurol. 2015 Mar;14(3):253-62.

19. Coyle-Gilchrist IT, Dick KM, Patterson K, Vázquez Rodríquez P, Wehmann E, Wilcox A, Lansdall CJ, Dawson KE, Wiggins J, Mead S, Brayne C, Rowe JB. Prevalence, characteristics, and survival of frontotemporal lobar degeneration syndromes. Neurology. 2016 May 3;86(18):1736-43.

20. Snowden JS, Thompson JC, Stopford CL, Richardson AMT, Gerhard A, Neary D, et al. The clinical diagnosis of early-onset dementias: diagnostic accuracy and clinicopathological relationships. Brain: a journal of neurology. 2011; 134(9):2478-92

21. Mesulam MM. Primary progressive aphasia and the language network. Neurology. 2013 Jul 30; 81(5): 456-62.

22. Nicholson AM, Rademakers R. What we know about TMEM106B in neurodegeneration. Acta Neuropathol. 2016 Nov; 132(5): 639-651.

23. Mackenzie IR, Neumann M. Molecular neuropathology of frontotemporal dementia: insights into disease mechanisms from postmortem studies. J Neurochem. 2016 Aug; 138 Suppl 1: 54-70. 
24. Rohrer JD, Guerreiro R, Vandrovcova J, Uphill J, Reiman D, Beck J, Isaacs AM, Authier A, Ferrari R, Fox NC, Mackenzie IR, Warren JD, de Silva R, Holton J, Revesz T, Hardy J, Mead S, Rossor MN. The heritability and genetics of frontotemporal lobar degeneration. Neurology. 2009 Nov 3;73(18):1451-6.

25. Rohrer JD, Warren JD. Phenomenology and anatomy of abnormal behaviours in primary progressive aphasia. J Neurol Sci. 2010 Jun 15; 293(1-2): 35-8.

26. Piguet O, Hodges JR. Behavioural-variant frontotemporal dementia: an update. Dement Neuropsychol. 2013 Jan-Mar; 7(1): 10-18.

27. Pottier C, Ravenscroft TA, Sanchez-Contreras M, Rademakers R. Genetics of FTLD: overview and what else we can expect from genetic studies. J Neurochem. 2016;138 Suppl 1:32-53

28. Rademakers R, Neumann M, Mackenzie I. Advances in understanding the molecular basis of frontotemporal dementia. Nat Rev Neurol. 2012;8:423-434

29. Pickering-Brown S, Rollinson S, Du Plessis D, Morrison K, Varma A, Richardson A et al. Frequency and clinical characteristics of progranulin mutation carriers in the Manchester frontotemporal lobar degeneration cohort: comparison with patients with MAPT and no known mutations. Brain. 2008;131:721-731

30. Seelaar H, Kamphorst W, Rosso S et al. Distict genetic forms of frontotemporal dementia. Neurology 2008;71:1220-1226

31. Bang J, Spina S, Miller B. Frontotemporal dementia. Lancel. 2015;386:1672-1682

32. Gijselinck I, Van Mossevelde S, van der Zee J, Sieben A, Philtjens S, Heeman B, et al. Loss of TBK1 is a frequent cause of frontotemporal dementia in a Belgian cohort. Neurology. 2015 Dec 15; 85(24): 2116-25.

33. Mishra A, Ferrari R, Heutink P, Hardy J, Pijnenburg Y, Posthuma D; International FTDGenomics Consortium. Gene-based association studies report genetic links for clinical subtypes of frontotemporal dementia. Brain. 2017 May 1; 140(5): 1437-1446.

34. Taskesen E, Mishra A, van der Sluis S, Ferrari R; International FTD-Genomics Consortium, Veldink JH, van Es MA, Smit AB, Posthuma D, Pijnenburg Y. Susceptible genes and disease mechanisms identified in frontotemporal dementia and frontotemporal dementia with Amyotrophic Lateral Sclerosis by DNA-methylation and GWAS. Sci Rep. 2017 Aug 21; 7(1): 8899. 
35. Warren JD, Rohrer JD, Schott JM, Fox NC, Hardy J, Rossor MN. Molecular nexopathies: a new paradigm of neurodegenerative disease. Trends Neurosci. 2013b Oct; 36(10): 561-9.

36. Mahoney CJ, Beck J, Rohrer JD, Lashley T, Mok K, Shakespeare T, Yeatman T, Warrington EK, Schott JM, Fox NC, Rossor MN, Hardy J, Collinge J, Revesz T, Mead S, Warren JD. Frontotemporal dementia with the C9ORF72 hexanucleotide repeat expansion: clinical, neuroanatomical and neuropathological features. Brain. 2012 Mar; 135(Pt 3): 736-50.

37. Whitwell JL, Josephs KA. Neuroimaging in frontotemporal lobar degeneration--predicting molecular pathology. Nat Rev Neurol. 2012 Jan 31; 8(3): 131-42.

38. Georgiadis K, Wray S, Ourselin S, Warren JD, Modat M. Computational modelling of pathogenic protein spread in neurodegenerative diseases. PLoS One. 2018 Feb 5;13(2):e0192518.

39. Sami S, Williams N, Hughes LE, Cope TE, Rittman T, Coyle-Gilchrist ITS, Henson RN, Rowe JB. Neurophysiological signatures of Alzheimer's disease and frontotemporal lobar degeneration: pathology versus phenotype. Brain. 2018 Aug 1; 141(8): 2500-2510.

40. Sommerlad A, Lee J, Warren J, Price G. Neurodegenerative disorder masquerading as psychosis in a forensic psychiatry setting. BMJ Case Rep. 2014 Jun 13;2014.

41. Ramanan S, Bertoux M, Flanagan E, Irish M, Piguet O, Hodges JR, Hornberger M. Longitudinal Executive Function and Episodic Memory Profiles in Behavioral-Variant Frontotemporal Dementia and Alzheimer's Disease. J Int Neuropsychol Soc. 2017 Jan; 23(1): 34-43.

42. Beck J, Rohrer JD, Campbell T, Isaacs A, Morrison KE, Goodall EF, Warrington EK, Stevens J, Revesz T, Holton J, Al-Sarraj S, King A, Scahill R, Warren JD, Fox NC, Rossor MN, Collinge J, Mead S. A distinct clinical, neuropsychological and radiological phenotype is associated with progranulin gene mutations in a large UK series. Brain. 2008 Mar; 131(Pt 3): 706-20.

43. Devenney E, Swinn T, Mioshi E, Hornberger M, Dawson KE, Mead S, Rowe JB, Hodges JR. The behavioural variant frontotemporal dementia phenocopy syndrome is a distinct entity - evidence from a longitudinal study. BMC Neurol. 2018 Apr 28;18(1):56.

44. Clark CN, Nicholas JM, Gordon E, Golden HL, Cohen MH, Woodward FJ, Macpherson K, Slattery CF, Mummery CJ, Schott JM, Rohrer JD, Warren JD. Altered sense of humor in dementia. J Alzheimers Dis. 2016;49(1):111-9. 
45. Ahmed RM, Goldberg ZL, Kaizik C, Kiernan MC, Hodges JR, Piguet O, Irish M. Neural correlates of changes in sexual function in frontotemporal dementia: implications for reward and physiological functioning. J Neurol. 2018 Aug 28. doi: 10.1007/s00415-018-9024-3. [Epub ahead of print]

46. Fletcher PD, Downey LE, Golden HL, Clark CN, Slattery CF, Paterson RW, Schott JM, Rohrer JD, Rossor MN, Warren JD. Auditory hedonic phenotypes in dementia: A behavioural and neuroanatomical analysis. Cortex. 2015a Jun; 67: 95-105.

47. Fletcher PD, Downey LE, Golden HL, Clark CN, Slattery CF, Paterson RW, Rohrer JD, Schott JM, Rossor MN, Warren JD. Pain and temperature processing in dementia: a clinical and neuroanatomical analysis. Brain. 2015b Nov; 138(Pt 11): 3360-72.

48. Erkkinen MG, Zúñiga RG, Pardo CC, Miller BL, Miller ZA. Artistic Renaissance in Frontotemporal Dementia. JAMA. 2018 Apr 3;319(13):1304-1306.

49. Devenney EM, Landin-Romero R, Irish M, Hornberger M, Mioshi E, Halliday GM, Kiernan MC, Hodges JR. The neural correlates and clinical characteristics of psychosis in the frontotemporal dementia continuum and the C9orf72 expansion. Neuroimage Clin. 2016 Dec 2; 13: 439-445.

50. Hardy CJ, Buckley AH, Downey LE, Lehmann M, Zimmerer VC, Varley RA, Crutch SJ, Rohrer JD, Warrington EK, Warren JD. The Language Profile of Behavioral Variant Frontotemporal Dementia. J Alzheimers Dis. 2016a; 50(2): 359-71.

51. Whitwell JL, Przybelski SA, Weigand SD, Ivnik RJ, Vemuri P, Gunter JL, Senjem ML, Shiung MM, Boeve BF, Knopman DS, Parisi JE, Dickson DW, Petersen RC, Jack CR Jr, Josephs KA. Distinct anatomical subtypes of the behavioural variant of frontotemporal dementia: a cluster analysis study. Brain. 2009 Nov;132(Pt 11):2932-46.

52. Chan D, Anderson V, Pijnenburg Y, Whitwell J, Barnes J, Scahill R, Stevens JM, Barkhof F, Scheltens P, Rossor MN, Fox NC. The clinical profile of right temporal lobe atrophy. Brain. 2009 May; 132(Pt 5): 1287-98.

53. Marshall CR, Hardy CJD, Russell LL, Clark CN, Bond RL, Dick KM, Brotherhood EV, Mummery CJ, Schott JM, Rohrer JD, Kilner JM, Warren JD. Motor signatures of emotional reactivity in frontotemporal dementia. Sci Rep. 2018b Jan 18; 8(1): 1030. 
54. Mahoney CJ, Rohrer JD, Goll JC, Fox NC, Rossor MN, Warren JD. Structural neuroanatomy of tinnitus and hyperacusis in semantic dementia. J Neurol Neurosurg Psychiatry. 2011 Nov;82(11):12748.

55. Marshall CR, Hardy CJD, Russell LL, Clark CN, Dick KM, Brotherhood EV, Bond RL, Mummery CJ, Schott JM, Rohrer JD, Kilner JM, Warren JD. Impaired Interoceptive Accuracy in Semantic Variant Primary Progressive Aphasia. Front Neurol. 2017 Nov 16; 8 :610.

56. Irish M, Addis DR, Hodges JR, Piguet O. Considering the role of semantic memory in episodic future thinking: evidence from semantic dementia. Brain 2012; 135:2178-2191

57. Sabodash V, Mendez MF, Fong S, Hsiao JJ. Suicidal behavior in dementia: a special risk in semantic dementia. Am J Alzheimers Dis Other Demen. 2013 Sep;28(6):592-9.

58. Kremen SA, Mendez MF, Tsai P-H, Teng E. Extrapyramidal signs in the primary progressive aphasias. Am J Alz Dis Other Dem 2011; 26:72-77.

59. Josephs KA, Whitwell JL, Murray ME, Parisi JE, Graff-Radford NR, Knopman DS et al. Corticospinal tract degeneration associated with TDP-43 type $\mathrm{C}$ pathology and semantic dementia. Brain 2013; 136:455-470.

60. Warren JD, Hardy CJ, Fletcher PD, Marshall CR, Clark CN, Rohrer JD, Rossor MN. Binary reversals in primary progressive aphasia. Cortex. 2016 Sep; 82: 287-289.

61. Josephs K, Duffy J, Strand E, Whitwell J, Layton K, Parisi J et al. Clinicopathological and imaging correlates of progressive aphasia and apraxia of speech. Brain 2006; 129:1385-1398.

62. Rohrer JD, Rossor MN, Warren JD. Syndromes of nonfluent primary progressive aphasia: a clinical and neurolinguistic analysis. Neurology. 2010a Aug 17;75(7):603-10.

63. Hardy CJ, Marshall CR, Golden HL, Clark CN, Mummery CJ, Griffiths TD, Bamiou DE, Warren JD. Hearing and dementia. J Neurol. 2016b Nov; 263(11): 2339-2354.

64. Rohrer JD, Rossor MN, Warren JD. Apraxia in progressive nonfluent aphasia. J Neurol. 2010b Apr;257(4):569-74.

65. Warren JD, Warren JE, Fox NC, Warrington EK. Nothing to say, something to sing: primary progressive dynamic aphasia. Neurocase. 2003 Apr; 9(2): 140-55. 
66. Magdalinou NK, Golden HL, Nicholas JM, Witoonpanich P, Mummery CJ, Morris HR et al. Verbal adynamia in parkinsonian syndromes: behavioural correlates and neuroanatomical substrate. Neurocase 2018, in press.

67. Rohrer JD, Paviour D, Bronstein AM, O'Sullivan SS, Lees A, Warren JD. Progressive supranuclear palsy syndrome presenting as progressive nonfluent aphasia: a neuropsychological and neuroimaging analysis. Mov Disord. 2010c Jan 30; 25(2): 179-188.

68. Rohrer JD, Crutch SJ, Warrington EK, Warren JD. Progranulin-associated primary progressive aphasia: a distinct phenotype? Neuropsychologia. 2010d Jan; 48(1): 288-97.

69. Rossor MN, Fox NC, Mummery CJ, Schott JM, Warren JD. The diagnosis of young-onset dementia. Lancet Neurol. 2010 Aug; 9(8): 793-806.

70. Ahmed RM, Murphy E, Davagnanam I, Parton M, Schott JM, Mummery CJ, Rohrer JD, Lachmann RH, Houlden H, Fox NC, Chataway J. A practical approach to diagnosing adult onset leukodystrophies. J Neurol Neurosurg Psychiatry. 2014 Jul; 85(7): 770-81.

71. Ossenkoppele R, Pijnenburg YA, Perry DC, Cohn-Sheehy BI, Scheltens NM, Vogel JW, et al. The behavioural/dysexecutive variant of Alzheimer's disease: clinical, neuroimaging and pathological features. Brain. 2015 Sep;138(Pt 9):2732-49.

72. Brodaty H, Seeher K, Gibson L. Dementia time to death: a systematic literature review on survival time and years of life lost in people with dementia. Int Psychogeriatr 2012; 24: 1034-45.

73. Kertesz A, McMonagle P, Blair M, Davidson W, Munoz DG. The evolution and pathology of frontotemporal dementia. Brain 2005; 128: 1996-2005.

74. Mendez MF, Shapira JS, McMurtray A, Licht E. Preliminary findings: behavioral worsening on donepezil in patients with frontotemporal dementia. Am J Geriatr Psychiatry. 2007 Jan; 15(1): 84-7.

75. Vercelletto M, Boutoleau-Bretonnière C, Volteau C, Puel M, Auriacombe S, Sarazin M, Michel BF, Couratier P, Thomas-Antérion C, Verpillat P, Gabelle A, Golfier V, Cerato E, Lacomblez L; French research network on Frontotemporal dementia. Memantine in behavioral variant frontotemporal dementia: negative results. J Alzheimers Dis. 2011;23(4):749-59.

76. Swartz JR, Miller BL, Lesser IM, Darby AL. Frontotemporal dementia: treatment response to serotonin selective reuptake inhibitors. J Clin Psychiatry. 1997 May; 58(5): 212-6. 
77. Deakin JB, Rahman S, Nestor PJ, Hodges JR, Sahakian BJ. Paroxetine does not improve symptoms and impairs cognition in frontotemporal dementia: a double-blind randomized controlled trial. Psychopharmacology (Berl). 2004 Apr; 172(4): 400-8.

78. Lebert F, Stekke W, Hasenbroekx C, Pasquier F. Frontotemporal dementia: a randomised, controlled trial with trazodone. Dement Geriatr Cogn Disord. 2004; 17(4): 355-9.

79. Herrmann N, Black SE, Chow T, Cappell J, Tang-Wai DF, Lanctôt KL. Serotonergic function and treatment of behavioral and psychological symptoms of frontotemporal dementia. Am J Geriatr Psychiatry. 2012 Sep; 20(9): 789-97.

80. Czarnecki K, Kumar N, Josephs KA. Parkinsonism and tardive antecollis in frontotemporal dementia--increased sensitivity to newer antipsychotics? Eur J Neurol. 2008 Feb; 15(2): 199-201.

81. Nomoto H, Matsubara Y, Ichimiya Y, Arai H. A case of frontotemporal dementia with sexual disinhibition controlled by aripiprazole. Psychogeriatrics. 2017 Nov; 17(6): 509-510.

82. Dick KM, van Swieten JC, Gerhard A, Le Ber I, Frisoni GB, Dickerson BC, et al. Symptom onset in genetic frontotemporal dementia. Alzheimers Dementia 2017; 13 Supplement 1: P1337.

83. Tsai RM, Boxer AL. Therapy and clinical trials in frontotemporal dementia: past, present, and future. J Neurochem. 2016 Aug; 138 Suppl 1: 211-21

84. Gordon E, Rohrer JD, Kim LG, Omar R, Rossor MN, Fox NC, Warren JD. Measuring disease progression in frontotemporal lobar degeneration: a clinical and MRI study. Neurology. 2010 Feb 23; 74(8): 666-73.

85. Okamura N, Harada R, Ishiki A, Kikuchi A, Nakamura T, Kudo Y. The development and validation of tau PET tracers: current status and future directions. Clin Transl Imaging. 2018; 6(4): 305-316.

86. Rohrer JD, Woollacott IO, Dick KM, Brotherhood E, Gordon E, Fellows A, Toombs J, Druyeh R, Cardoso MJ, Ourselin S, Nicholas JM, Norgren N, Mead S, Andreasson U, Blennow K, Schott JM, Fox NC, Warren JD, Zetterberg H. Serum neurofilament light chain protein is a measure of disease intensity in frontotemporal dementia. Neurology. 2016 Sep 27; 87(13): 1329-36.

87. Feneberg E, Steinacker P, Volk AE, Weishaupt JH, Wollmer MA, Boxer A, Tumani H, Ludolph AC, Otto M. Progranulin as a candidate biomarker for therapeutic trial in patients with ALS and FTLD. J Neural Transm (Vienna). 2016 Mar; 123(3): 289-96. 
88. Borroni B, Benussi A, Premi E, Alberici A, Marcello E, Gardoni F, Di Luca M, Padovani A. Biological, Neuroimaging, and Neurophysiological Markers in Frontotemporal Dementia: Three Faces of the Same Coin. J Alzheimers Dis. 2018; 62(3): 1113-1123.

89. Foiani MS, Woollacott IO, Heller C, Bocchetta M, Heslegrave A, Dick KM, Russell LL, Marshall CR, Mead S, Schott JM, Fox NC, Warren JD, Zetterberg H, Rohrer JD. Plasma tau is increased in frontotemporal dementia. J Neurol Neurosurg Psychiatry. 2018 Aug;89(8):804-807.

90. Woollacott IOC, Nicholas JM, Heslegrave A, Heller C, Foiani MS, Dick KM, Russell LL, Paterson RW, Keshavan A, Fox NC, Warren JD, Schott JM, Zetterberg H, Rohrer JD. Cerebrospinal fluid soluble TREM2 levels in frontotemporal dementia differ by genetic and pathological subgroup. Alzheimers Res Ther. 2018 Aug 16; 10(1): 79.

91. Ahmed RM, Ke YD, Vucic S, Ittner LM, Seeley W, Hodges JR, Piguet O, Halliday G, Kiernan MC. Physiological changes in neurodegeneration - mechanistic insights and clinical utility. Nat Rev Neurol. 2018 May; 14(5): 259-271.

92. Kim WS, Jary E, Pickford R, He Y, Ahmed RM, Piguet O, Hodges JR, Halliday GM. Lipidomics Analysis of Behavioral Variant Frontotemporal Dementia: A Scope for Biomarker Development. Front Neurol. 2018 Feb 28; 9: 104

93. Marshall CR, Hardy CJD, Allen M, Russell LL, Clark CN, Bond RL, Dick KM, Brotherhood EV, Rohrer JD, Kilner JM, Warren JD. Cardiac responses to viewing facial emotion differentiate frontotemporal dementias. Ann Clin Transl Neurol. 2018c Apr 14; 5(6): 687-696.

94. Hu WT, McMillan C, Libon D, Leight S, Forman M, Lee VM, Trojanowski JQ, Grossman M. Multimodal predictors for Alzheimer disease in nonfluent primary progressive aphasia. Neurology. 2010 Aug 17; 75(7): 595-602.

95. Almeida S, Gao F, Coppola G, Gao FB. Suberoylanilide hydroxamic acid increases progranulin production in iPSC-derived cortical neurons of frontotemporal dementia patients. Neurobiol Aging. 2016 Jun; 42: 35-40.

96. Capell A, Liebscher S, Fellerer K, Brouwers N, Willem M, Lammich S, Gijselinck I, Bittner T, Carlson AM, Sasse F, Kunze B, Steinmetz H, Jansen R, Dormann D, Sleegers K, Cruts M, Herms J, Van Broeckhoven C, Haass C. Rescue of progranulin deficiency associated with frontotemporal lobar degeneration by alkalizing reagents and inhibition of vacuolar ATPase. J Neurosci. 2011 Feb 2; 31(5): 1885-94. 
97. Ahmed RM, Irish M, van Eersel J, Ittner A, Ke YD, Volkerling A, van der Hoven J, Tanaka K, Karl T, Kassiou M, Kril JJ, Piguet O, Götz J, Kiernan MC, Halliday GM, Hodges JR, Ittner LM. Mouse models of frontotemporal dementia: A comparison of phenotypes with clinical symptomatology. Neurosci Biobehav Rev. 2017 Mar; 74(Pt A): 126-138.

98. Wild EJ, Tabrizi SJ. Therapies targeting DNA and RNA in Huntington's disease. Lancet Neurol. 2017 Oct; 16(10): 837-847.

99. Hardy CJD, Marshall CR, Bond RL, Russell LL, Dick K, Ariti C, Thomas DL, Ross SJ, Agustus JL, Crutch SJ, Rohrer JD, Bamiou DE, Warren JD. Retained capacity for perceptual learning of degraded speech in primary progressive aphasia and Alzheimer's disease Alzheimers Res Ther. 2018; 10(1): 70 .

100. Finger E, Berry S, Cummings J, Coleman K, Hsiung R, Feldman HH, Boxer A. Adaptive crossover designs for assessment of symptomatic treatments targeting behaviour in neurodegenerative disease: a phase 2 clinical trial of intranasal oxytocin for frontotemporal dementia (FOXY). Alzheimers Res Ther. 2018 Sep 27; 10(1): 102.

101. Carthery-Goulart MT, da Silveira AC, Machado TH, Mansur LL, Parente MAMP, Senaha MLH et al. Nonpharmacological interventions for cognitive impairments following primary progressive aphasia: a systematic review of the literature. Dem Neuropsychol 2013; 7: 122-131

102. Tsapkini K, Webster KT, Ficek BN, Desmond JE, Onyike CU, Rapp B, Frangakis CE, Hillis AE. Electrical brain stimulation in different variants of primary progressive aphasia: A randomized clinical trial. Alzheimers Dement (N Y). 2018 Sep 5; 4: 461-472.

103. Tsakiris M, Hesse MD, Boy C, et al. Neural signatures of body ownership: a sensory network for bodily self-consciousness. Cereb Cort 2007; 17: 2235-44.

104. Downey LE, Fletcher PD, Golden HL, Mahoney CJ, Agustus JL, Schott JM, Rohrer JD, Beck J, Mead S, Rossor MN, Crutch SJ, Warren JD. Altered body schema processing in frontotemporal dementia with C9ORF72 mutations. J Neurol Neurosurg Psychiatry. 2014 Sep; 85(9): 1016-23.

105. Guo CC, Sturm VE, Zhou J, Gennatas ED, Trujillo AJ, Hua AY, Crawford R, Stables L, Kramer JH, Rankin K, Levenson RW, Rosen HJ, Miller BL, Seeley WW. Dominant hemisphere lateralization of cortical parasympathetic control as revealed by frontotemporal dementia. Proc Natl Acad Sci U S A. 2016 Apr 26; 113(17): E2430-9. 


\section{Box 1. Deconstructing C9orf 72 -associated frontotemporal dementia}

The clinical phenotype of $C 9$ orf72 mutations (the most common genetic cause of FTD) is complex but neuropsychiatric features, including anxiety and somatically focussed delusions and misperceptions, are often prominent ${ }^{36,49}$. Neuropathologically, these cases have deposition of pathogenic proteins TDP43 and p62 targeting a distributed cortico-subcortical network including cerebellum, thalamus, insula and parietal lobe: this network has been shown to be affected early in the evolution of disease, many years prior to onset of typical clinical symptoms ${ }^{18,36}$ and its involvement correlates with the presence of neuropsychiatric symptoms ${ }^{49}$. In the healthy brain, this network mediates body schema processing, while derangements of body schema have been shown to produce schizotypal features similar to those observed in C9orf72 mutation carriers ${ }^{103}$ : and indeed, psychophysiological abnormalities of body schema processing (tactile discrimination, self-nonself differentiation, pain and temperature homeostasis) have been shown to differentiate C9orf72 mutation carriers from other forms of $\mathrm{FTD}^{47,104}$.

Taken together, these findings unite a molecular pathological signature with a complex behavioural phenotype, via a physiological mechanism instantiated in specific brain network disintegration. C9orf72-associated FTD could be considered a 'molecular nexopathy': a coherent conjunction of pathogenic protein, neural network and clinical phenotype ${ }^{35}$. Deconstruction of other complex phenotypes within the FTD spectrum and identification of specific physiological markers may allow analogous linkages to be established for a range of pathogenic proteins; abnormal physiological coding of internal and externally generated emotional signals is richly differentiated across the FTD spectrum $^{53,55,93,105}$ and may yield quantifiable proxies of socio-emotional behavioural disturbances that are difficult to measure directly. 
Table 1. A problem-oriented management 'checklist' for frontotemporal dementia

\begin{tabular}{|c|c|}
\hline Problem & Possible strategies \\
\hline \multicolumn{2}{|l|}{ Optimising quality of life } \\
\hline Employment & $\begin{array}{l}\text { Occupational health assessments; vocational counselling, redeployment } \\
\text { and rehabilitation; medical retirement }\end{array}$ \\
\hline Finances & $\begin{array}{l}\text { Expert financial advice; review banking arrangements; assessment of } \\
\text { eligibility for allowances, disability support }\end{array}$ \\
\hline Safe-guarding & $\begin{array}{l}\text { Identify and assess any physical / emotional / socio-economic / forensic } \\
\text { risks to patient or potentially vulnerable contacts (children, elderly); } \\
\text { engage family, other caregivers, social services as appropriate }\end{array}$ \\
\hline Driving & $\begin{array}{l}\text { Inform licensing authority and insurer (legal frameworks); assess current } \\
\text { safety and competence from caregiver report; assess relevant skills } \\
\text { (judgement and impulse control, praxis, motor, visuospatial); practical } \\
\text { driving test in borderline cases; limit access to motor vehicles if required }\end{array}$ \\
\hline Home environment & $\begin{array}{l}\text { Occupational therapy assessment of potential hazards (e.g., falls risk), } \\
\text { barriers to mobility; home modifications (e.g., rails, safety locks) }\end{array}$ \\
\hline \multicolumn{2}{|l|}{ Controlling symptoms } \\
\hline Impaired communication & $\begin{array}{l}\text { Speech and language therapy; communication aids and devices; alert } \\
\text { card or bracelet }\end{array}$ \\
\hline $\begin{array}{l}\text { Disinhibition, impulsivity, } \\
\text { wandering }\end{array}$ & $\begin{array}{l}\text { Environmental modification; supervision; avoid triggers; programmed } \\
\text { activities (ensure adequate mental stimulation); limit setting and } \\
\text { redirection; tracking devices }\end{array}$ \\
\hline $\begin{array}{l}\text { Apathy, lack of initiative / } \\
\text { empathy }\end{array}$ & $\begin{array}{l}\text { Reinterpretation (for caregivers); routines; engage retained interests } \\
\text { (e.g., puzzles, music); assess mood / impact on care; exclude intercurrent } \\
\text { comorbidity }\end{array}$ \\
\hline Depression, anxiety & Psychological support and counselling; consider SSRI \\
\hline Agitation, aggression & $\begin{array}{l}\text { Avoid triggers; reassurance; displacement activities; exclude intercurrent } \\
\text { comorbidity; consider SSRI, new generation neuroleptic }\end{array}$ \\
\hline Delusions, hallucinations & Consider new generation neuroleptic if distressing / disruptive \\
\hline Abnormal eating behaviour, & Dietary, dental and swallowing assessments; monitor weight; control \\
\hline
\end{tabular}




\begin{tabular}{|c|c|}
\hline dysphagia & $\begin{array}{l}\text { access to food and/or alcohol; discussion of assisted feeding where } \\
\text { appropriate; consider SSRI (hyperphagia) }\end{array}$ \\
\hline $\begin{array}{l}\text { Hypersexuality }{ }^{*} \text {, other } \\
\text { compulsions }\end{array}$ & $\begin{array}{l}\text { Avoid triggers; limit setting and redirection; substitute activities; } \\
\text { consider SSRI }\end{array}$ \\
\hline Sleep disturbance & $\begin{array}{l}\text { Sleep routines and 'hygiene'; avoid evening caffeine / alcohol, daytime } \\
\text { naps; regular exercise; consider sleep study to exclude nocturnal } \\
\text { seizures, sleep apnoea, parasomnia; review medication list; consider } \\
\text { SSRI with sedative potential (e.g., mirtazapine), melatonin }\end{array}$ \\
\hline $\begin{array}{l}\text { Abnormal pain, temperature } \\
\text { perception }\end{array}$ & $\begin{array}{l}\text { Care with medical assessments, interpretation of symptoms (avoid } \\
\text { under- / over-investigation) }\end{array}$ \\
\hline Motor disability & $\begin{array}{l}\text { Environmental modification; mobility aids; physiotherapy; review } \\
\text { medication list; consider trial of levodopa / dopamine agonist }\end{array}$ \\
\hline $\begin{array}{l}\text { Bladder and bowel } \\
\text { dysfunction }\end{array}$ & $\begin{array}{l}\text { Environmental modification (cues / assistance with toileting, access to } \\
\text { toilet); continence / urological assessment (address prostatism, other } \\
\text { intercurrent factors); exclude infection; address constipation; pads, } \\
\text { diapers; new generation medications for bladder overactivity where } \\
\text { indicated }\end{array}$ \\
\hline Intercurrent comorbidities & $\begin{array}{l}\text { Assess and correct visual, hearing deficits; optimisation of reversible } \\
\text { vascular risk factors; age-appropriate health screens; liaise with surgical } \\
\text { and other specialties as indicated }\end{array}$ \\
\hline \multicolumn{2}{|l|}{$\begin{array}{l}\text { Supporting caregivers and } \\
\text { families }\end{array}$} \\
\hline Loss of income & Carer allowance \\
\hline Loss of social networks & Contact regional / national support groups \\
\hline Emotional distress & $\begin{array}{l}\text { Education and reinterpretation of behaviours; counselling (couple / } \\
\text { individual / bereavement) and assess carer's mental health if indicated }\end{array}$ \\
\hline Care burden & $\begin{array}{l}\text { Periodically reassess level of care required, adequacy of provision (e.g., } \\
\text { night-time); day centres and related programmed activities; external / } \\
\text { social care; community nurses and health visitors; assist decision- } \\
\text { making re residential care }\end{array}$ \\
\hline Caregiver burnout & $\begin{array}{l}\text { Arrange programmed respite; empower asking for help; engage available } \\
\text { social networks; formal psychological therapy for carers }\end{array}$ \\
\hline
\end{tabular}




\begin{tabular}{|c|c|}
\hline Special needs & $\begin{array}{l}\text { Involve school and child counsellors for younger children; assess impact } \\
\text { if patient has been acting as a carer }\end{array}$ \\
\hline \multicolumn{2}{|l|}{ Future planning } \\
\hline $\begin{array}{l}\text { Decision-making: financial, } \\
\text { testamentary, medical }\end{array}$ & $\begin{array}{l}\text { Arrangements for power of attorney, will; assessment of capacity } \\
\text { (should be dynamic and specific) }\end{array}$ \\
\hline Living arrangements & $\begin{array}{l}\text { Future-proofing of home set-up and local area; access to services; scope } \\
\text { day centres and residential care options; inform local shopkeepers, } \\
\text { police }\end{array}$ \\
\hline Medical care arrangements & $\begin{array}{l}\text { Engage local GP (ideally, ensure continuity), community mental health } \\
\text { team and/or neurologist; palliative care services as appropriate }\end{array}$ \\
\hline End-of-life care & Advance decisions, living will \\
\hline $\begin{array}{l}\text { Genetic implications for } \\
\text { family }\end{array}$ & $\begin{array}{l}\text { Personalised discussion with family members; referral to clinical } \\
\text { geneticist for discussion of pre-symptomatic genetic screening }\end{array}$ \\
\hline
\end{tabular}

This table summarises some key themes and common problems in the management of patients with frontotemporal dementia, together with management strategies that we have found to be useful in our clinical practice. A number of problems are relevant across frontotemporal dementia syndromes, though issues around conduct and socio-emotional awareness tend to be more significant earlier in behavioural variant frontotemporal dementia and communication problems more salient in the progressive aphasias. SSRI, selective serotonin reuptake inhibitor (e.g. citalopram, trazodone); *most patients have reduced libido 

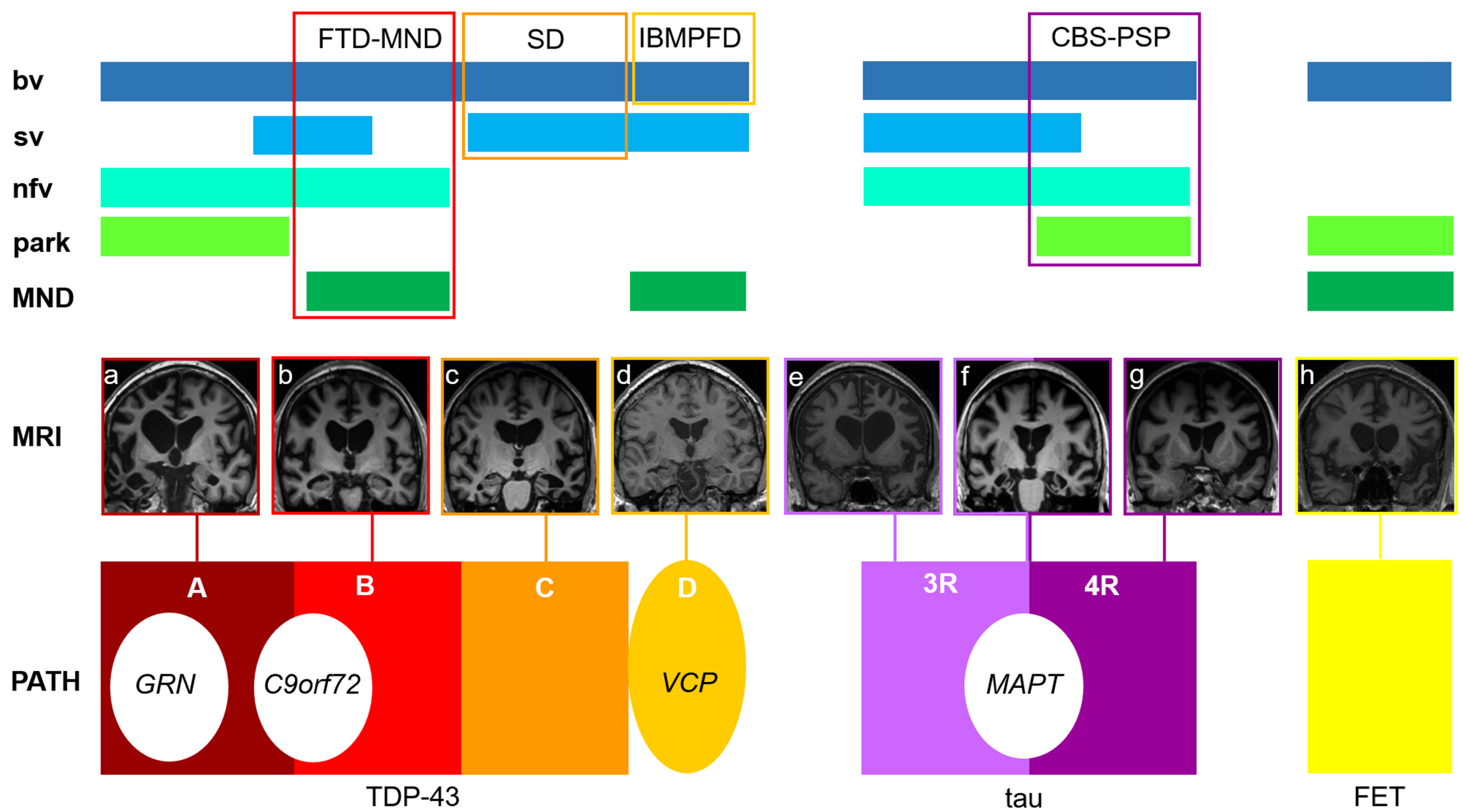

tau

FET

Figure 1. The histopathological, genetic, neuroanatomical and clinical spectrum of frontotemporal dementia. Abnormal accumulation of transactive response DNA-binding protein 43 (TDP-43) or hyperphosphorylated tau (oblongs, bottom) account for most cases of FTD; these proteinopathies are further subclassified on morphological or immunohistochemical grounds into TDP types A, B, C and D and tau principally containing three-repeat (3R, classical Pick's disease) or four-repeat (4R) microtubule binding domains. A minority of FTD cases have a proteinopathy in the FET (fused in sarcoma (FUS), Ewing's sarcoma, TATA-binding protein-associated factor 15) spectrum or rarely, lack pathological accumulation of any of these proteins. Mutations of three major genes (ellipses, bottom) account for a substantial proportion of TDP-43 (progranulin gene, $\boldsymbol{G R N}$; chromosome 9 open reading frame 72, $\boldsymbol{C 9 o r f} 72$ )) and tau (microtubule-associated protein 
tau gene, MAPT) cases. Mutations of a number of other genes can also cause FTD, including rare cases with mutations of the valosincontaining protein gene $(\boldsymbol{V C P})$ and TDP type D pathology. Vertical columns indicate the correspondence between molecular pathology (bottom), neuroanatomy (brain MRI, middle panels) and clinical features (filled oblongs, top), which varies across the FTD spectrum (see text). T1-weighted coronal MRI sections (presented with the left cerebral hemisphere on the right) show regional atrophy profiles produced by particular molecular pathologies, including the following characteristic associations: a, strikingly asymmetric atrophy of cerebral hemispheres with $G R N$ mutation, c, asymmetric, predominantly antero-mesial temporal lobe atrophy with TDP type C; e, asymmetric atrophy with classical Pick's disease; f, relatively symmetric, predominantly antero-mesial temporal lobe atrophy with $M A P T$ mutation; $\mathbf{h}$, disproportionately severe caudate atrophy with FUS. Regional atrophy profiles with C9orf72 mutations (b), VCP mutations (d), Pick's disease (e) and corticobasal degeneration (g) are variable (d illustrates that atrophy can be minimal even with proven FTD pathology). Clinically, behavioural variant (bv)FTD can be produced by any pathology and has a variety of MRI associations (compare a, b, $\mathbf{d}, \mathbf{f}, \mathbf{h}$ ); nonfluent - agrammatic variant (nfv) PPA is more frequently (but not exclusively) underpinned by tau pathology and associated with predominantly left anterior peri-Sylvian atrophy of variable severity (e, g), while semantic variant (sv) PPA is most often underpinned by TDP type $\mathrm{C}$ pathology and has a highly consistent MRI profile (c). Intersecting these canonical FTD syndromes, certain pathologies are associated with particular constellations of clinical features (unfilled oblongs, top), notably: TDP type B pathology with motor neuron disease (MND); TDP type C pathology with semantic dementia (SD; svPPA plus nonverbal semantic impairment); VCP mutations with inclusion body myopathy, Paget's disease of bone and frontal dementia (IBMPFD); and 4R tau pathology with atypical parkinsonism (park), corticobasal and progressive supranuclear palsy syndromes (CBS - PSP). Figure 2 presents a diagnostic synthesis of these various associations. 


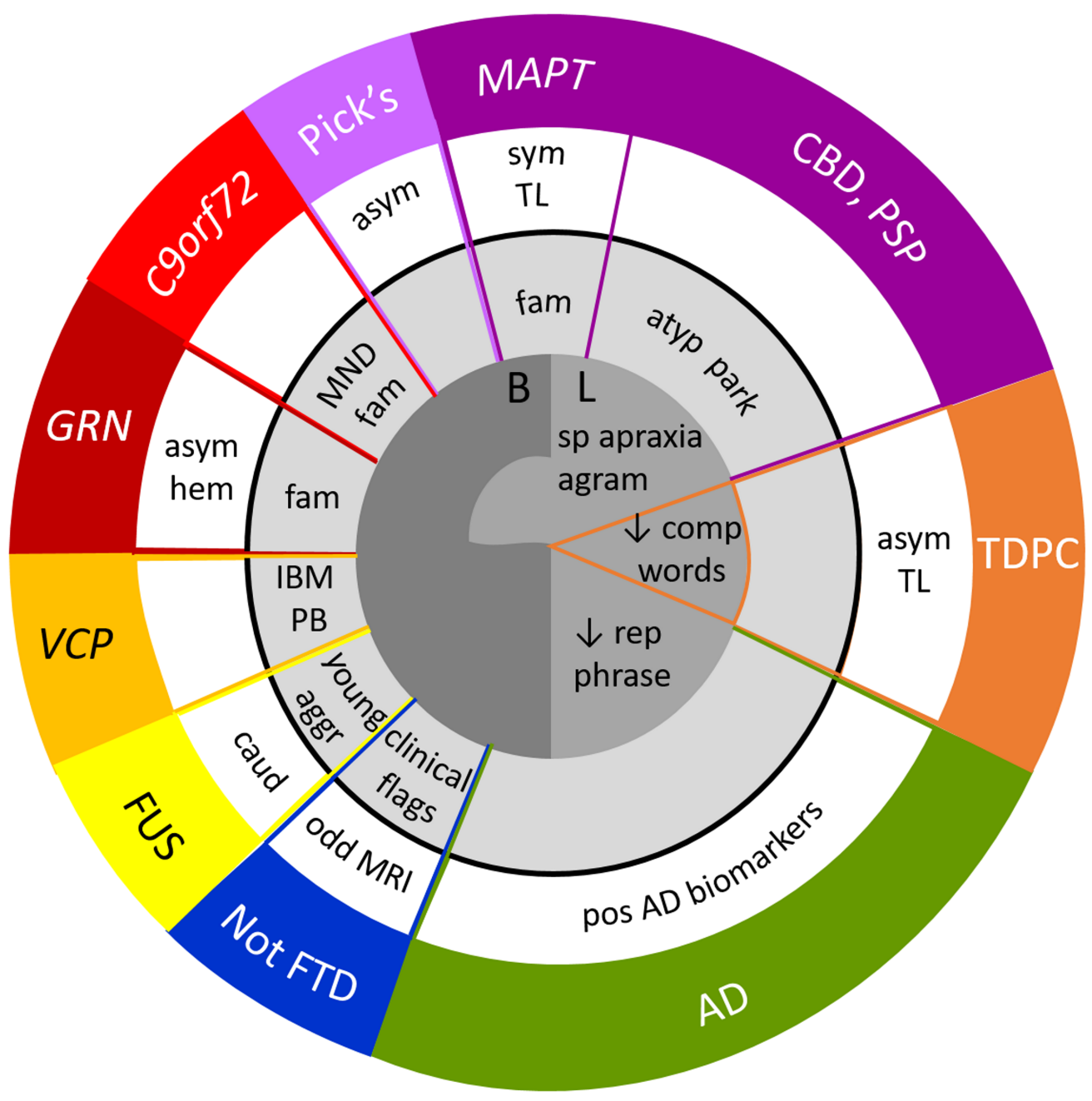

Figure 2. A 'diagnostic mandala' for frontotemporal dementias. Certain combinations of clinical features (central grey circles) and investigation findings (white circle) most usefully define phenotypes and predict particular molecular pathologies in the FTD spectrum (colour coded on outer circle; see also Figure 1). Core behavioural (B) and language (L) presentations correspond to the major variant syndromes of bvFTD and PPA; aphasic presentations can be subclassified into the major PPA variants according to whether the key clinical feature is impaired speech production (speech apraxia, sp apraxia or agrammatism, agram; nfvPPA), impaired single word comprehension (comp words; svPPA) or impaired repetition of phrases but relatively intact repetition of single words (rep phrase; logopenic aphasia) (see text). A history of similarly affected family members (fam), particularly an autosomal dominant inheritance pattern, is an important clue to a causative genetic mutation. Among these, clinical features of motor neuron disease (MND) predict a C9orf72 mutation (TDP-B pathology) and the rare constellation of inclusion body myopathy (IBM) and Paget's disease of bone (PB) predicts a $V \boldsymbol{C P}$ mutation; while on MRI, strongly asymmetric atrophy predominantly affecting one cerebral hemisphere with parietal extension (asym hem) predicts a $\boldsymbol{G} \boldsymbol{R} \boldsymbol{N}$ mutation (TDP-A pathology) and relatively symmetric, focal anterior temporal lobe atrophy (sym TL) predicts a MAPT mutation (see Figure 1). These patterns warrant genetic screening with appropriate family counselling. Among diseases that are usually sporadic, atypical parkinsonism with features of corticobasal syndrome, 
postural instability or supranuclear gaze palsy (atyp park) tends to predict a tauopathy such as corticobasal degeneration (CBD) or progressive supranuclear palsy (PSP); svPPA with strongly asymmetric focal anterior temporal lobe atrophy (asym TL) on MRI predicts TDP type C (TDPC) pathology; aggressive disease with young onset (young aggr) and severe caudate atrophy (caud) on MRI is characteristic of FUS pathology; while classical Pick's disease may present with bvFTD, nfvPPA or atypical PPA associated with asymmetric atrophy (asym) of variable distribution on MRI. Logopenic aphasia or (less commonly) bvFTD associated with positive Alzheimer's disease biomarkers (pos AD biomarkers; raised CSF total tau:beta-amyloid ${ }_{1-42}$ ratio or positive amyloid-PET scan) predict underlying Alzheimer's pathology; while some patients will have other pathologies outside the primary FTD spectrum (not FTD), generally signalled by clinical and/or MRI features atypical for FTD. 